International Journal of Biology, Pharmacy and Allied Seiences (IJBPAS) 'A Bridge Betuen Caboratory and Qnendo'

WWw.jibpas.com

KNOWLEDGE AND PERCEPTION REGARDING BLUETOOTH BRUSHING AMONG GENERAL POPULATION - A QUESTIONNAIRE SURVEY

\title{
SELVAPRIYA $S^{1}$, SASANKA $\mathrm{K}^{2 *}$, GHEENA $S^{3}$, AND GANAPATHY $\mathrm{D}^{4}$
}

1: Saveetha Dental College and Hospitals, Saveetha Institute of Medical and Technical Sciences, Saveetha University, Chennai, Tamilnadu, India

2: Department of Prosthodontics, Saveetha Dental College and Hospitals, Saveetha Institute of Medical and Technical Sciences, Saveetha University, Chennai, Tamilnadu, India

3: Department of Oral Pathology, Saveetha Dental College and Hospitals Saveetha Institute of

Medical and Technical Sciences, Saveetha University, Chennai, Tamilnadu, India

4: Department of Prosthodontics, Saveetha Dental College and Hospitals, Saveetha Institute of

Medical and Technical Sciences, Saveetha University, Chennai, Tamilnadu, India

*Corresponding Author: E Mail: Dr. Keerthi Sasanka: keerthis.sdc@saveetha.com

Received 19 ${ }^{\text {th }}$ March 2021; Revised 25 ${ }^{\text {th }}$ April. 2021; Accepted 20 ${ }^{\text {th }}$ May 2021; Available online $1^{\text {st }}$ Aug. 2021

\section{https://doi.org/10.31032/IJBPAS/2021/10.8.1046}

\section{ABSTRACT}

Tooth brushing is an important medium for maintaining good oral hygiene, and hence there arises a need to replace toothbrushes at a regular interval. Electric toothbrushes are comfortable and they improve the efficacy of plaque control and gingivitis. Questionnaire was prepared and administered to 100 participants through google forms an online survey. The study was approved by the scientific review board, Saveetha Dental College, Chennai. The total number of questions is 10 and the answers obtained from the participants are recorded and the answers given by each question are represented in the form of pie charts. A total of 100 participants were included in the study around $57.8 \%$ of participants like to brush their teeth with an electric toothbrush. $60.6 \%$ of participants are willing to purchase an electric toothbrush. $26.6 \%$ of 
participants are using electric toothbrushes in our study. The awareness and knowledge of bluetooth brushing habits and care towards their oral hygiene is literally low.

\section{Keywords: Electric toothbrush; Plaque; Gingivitis; Dental caries}

\section{INTRODUCTION}

The promotion of excellent oral hygiene is advocated and supported by the world Health bodies [1-3]. The adoption of preventive strategies, both at the individual and population level, helps reduce the negative impact of oral diseases including improving the standard of life. Health behaviors are crucial indicators of oral health status [4]. Effective and efficient oral hygiene practices are a necessary tool for achieving good oral health [5-7]. Therefore, to attain and maintain good oral hygiene, and forestall tooth decay and disease, regular tooth brushing using fluoride-containing toothpaste a minimum of twice every day is usually recommended. The utilization of floss and other oral hygiene aids items for the cleaning of contact surfaces is additionally important for effective plaque removal [8].

Powered toothbrush was invented in 1939, Fredrick Tonberg, Swedish watchmaker in the US made plaque control easier [9]. Powered toothbrush is recommended for disabled and hospitalized patients. It has a multi-directional power brush to reduce the incidence of gingivitis and plaque, in comparison to regular side-to- side brushing [10, 11]. An electric toothbrush performs rotations of its bristles and cleans hard to reach places. Most studies report performances equivalent to those of manual brushings, the powered brushing has significant decrease in plaque and gingivitis. An additional timer and pressure sensors can encourage a more efficient cleaning process [12].

Bluetooth brushes are often classified according to the speed of their movements as: standard power toothbrushes, sonic toothbrushes, or ultrasonic toothbrushes [13]. Any electric toothbrush is technically an influential toothbrush. If the motion of the toothbrush is sufficiently rapid to provide a hum in the audible frequency range $(20 \mathrm{~Hz}$ to 20,000 Hz) [14], it can be classified as a sonic toothbrush [15]. Any toothbrush with movement faster than this limit can be classified as an ultrasonic toothbrush. Certain ultrasonic toothbrushes, such because the Megasonex and also the Ultreo, have both sonic and ultrasonic movements. Studies have proved that powered toothbrushes end in significant reduction of plaque and gingivitis [16, 17]. Previously our team had 
conducted numerous studies and review on upcoming topics [7, 18-26].

There are so many studies about knowledge and awareness of dental diseases and treatment [24, 25, 27-31], many authors have come forward and have done more studies about knowledge and awareness of Bluetooth brush.

\section{MATERIALS AND METHODS}

An Online survey was conducted with a self structured questionnaire with a sample size of hundred participants comprising the general population. The questionnaire consists of Questions that help in collecting socio-economic data, questions that help in provoking awareness among the participants and questionnaires also related to the awareness and knowledge of Bluetooth brushing. The questionnaire was validated in the standard manner. measures such as selection of participants randomly, placing restrictions over the participant population and age groups are taken to minimise the bias occurring in sampling. The questionnaire was circulated using the online platform "google form" and the link was circulated through the social media to the respondents. The responses were recorded and with the collected responses descriptive analysis such as chi- square test was performed and the results of the analysis test carried out was represented in the form of pie chart and bar graphs.

\section{RESULT AND DISCUSSION}

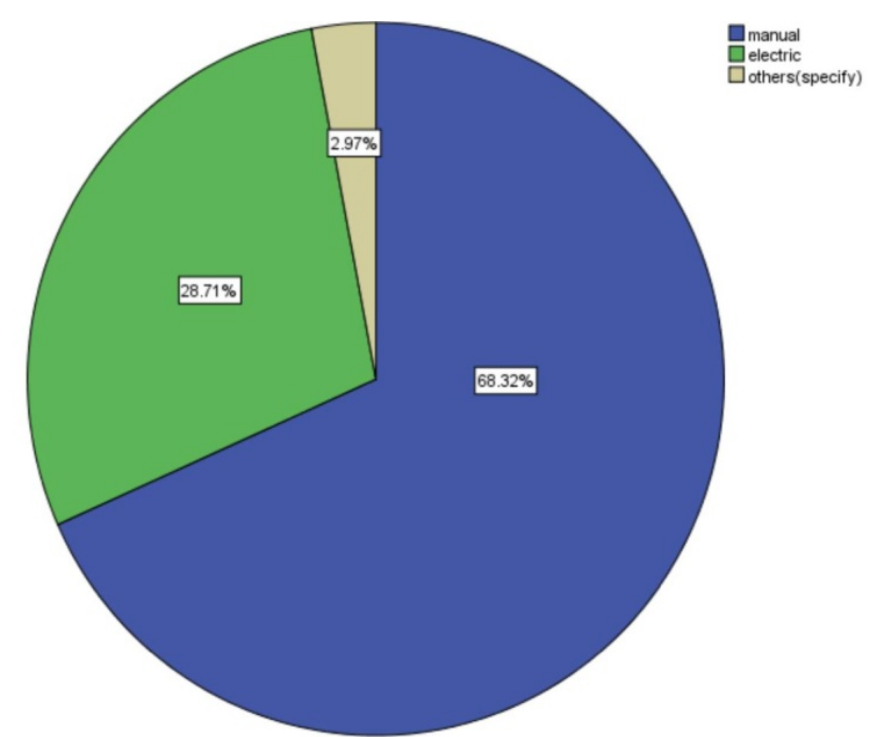

Figure 1: This graph represents the distribution of study participants based on types of brushes used, $68.32 \%$ of participants use manual brushing, $28.71 \%$ of participants use electric toothbrushes and $2.97 \%$ of participants use other than manual or electric toothbrushes. 


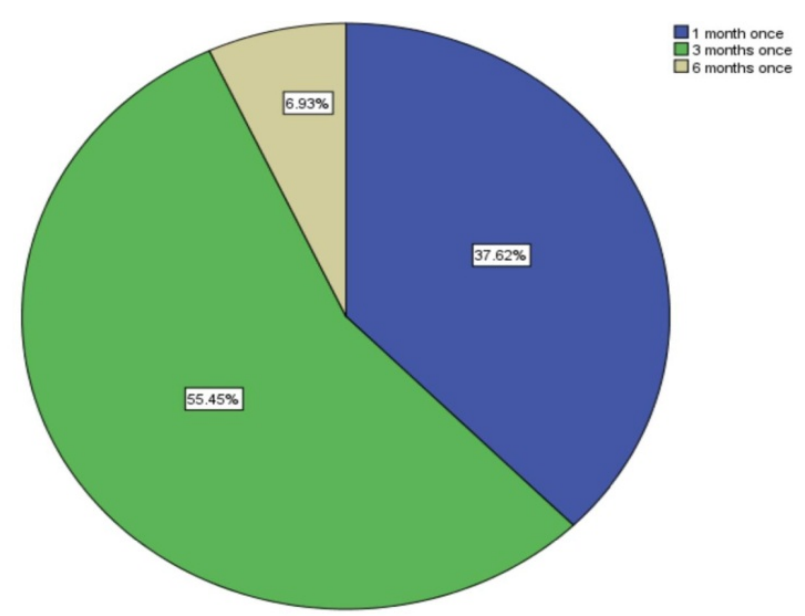

Figure 2: This graph represents the distribution of study population based on frequency of changing toothbrush, 37.62\% of participants change brush once in a month, $55.45 \%$ of participants change brush once in 3 months and $6.93 \%$ of participants change brush once in 6 months.

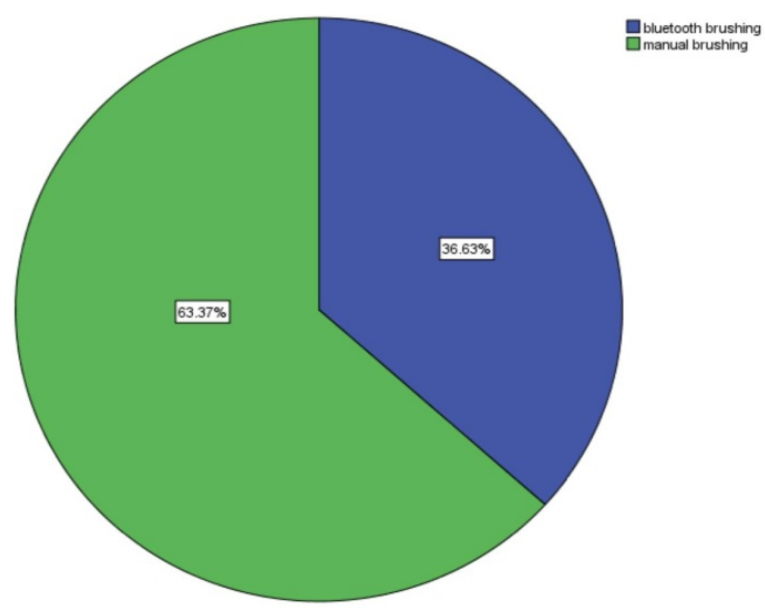

Figure 3: This graph represents the distribution of study population based on preference of type of brushing, $63.37 \%$ of participants responded they prefer manual brushing and $36.63 \%$ of participants responded they prefer Bluetooth brushing.

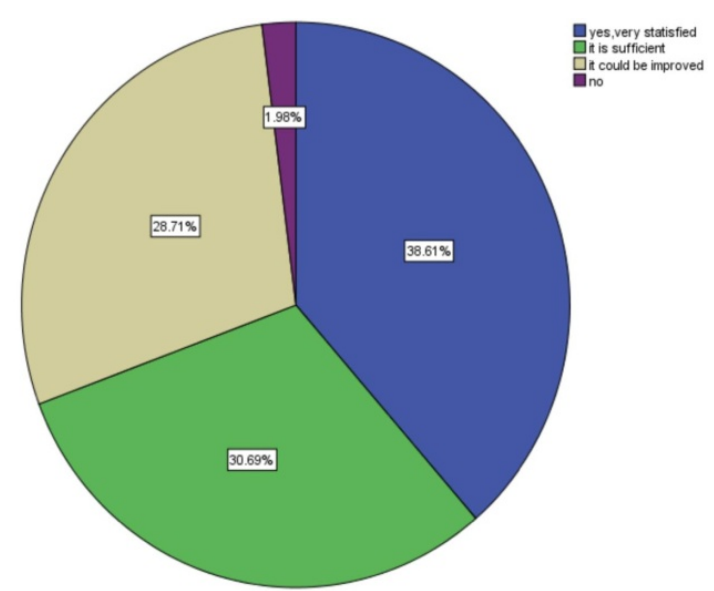

Figure 4: This graph represents the distribution of study population based on the current way of cleaning teeth, 38.61\% of participants are very satisfied, $30.69 \%$ of participants feel the current way of cleaning teeth was sufficient, $28.71 \%$ of participants like to improve the current way of cleaning and $1.96 \%$ of participants were not satisfied . 


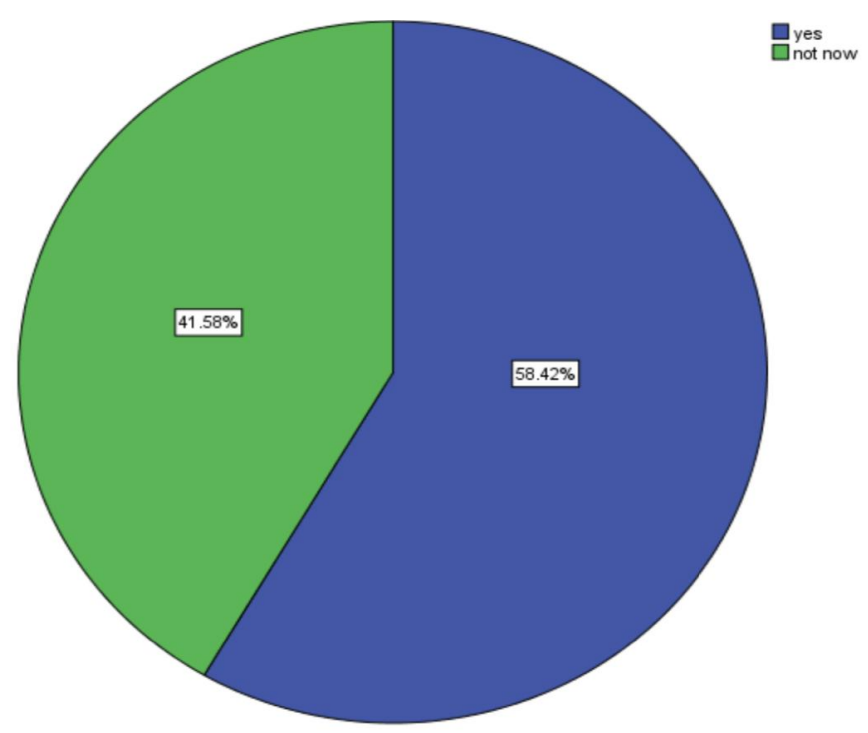

Figure 5: This graph represents the distribution of study population based on readiness to purchase an electric toothbrush, $58.42 \%$ of participants responded willing to purchase an electric toothbrush and $41.58 \%$ of participants responded not now.

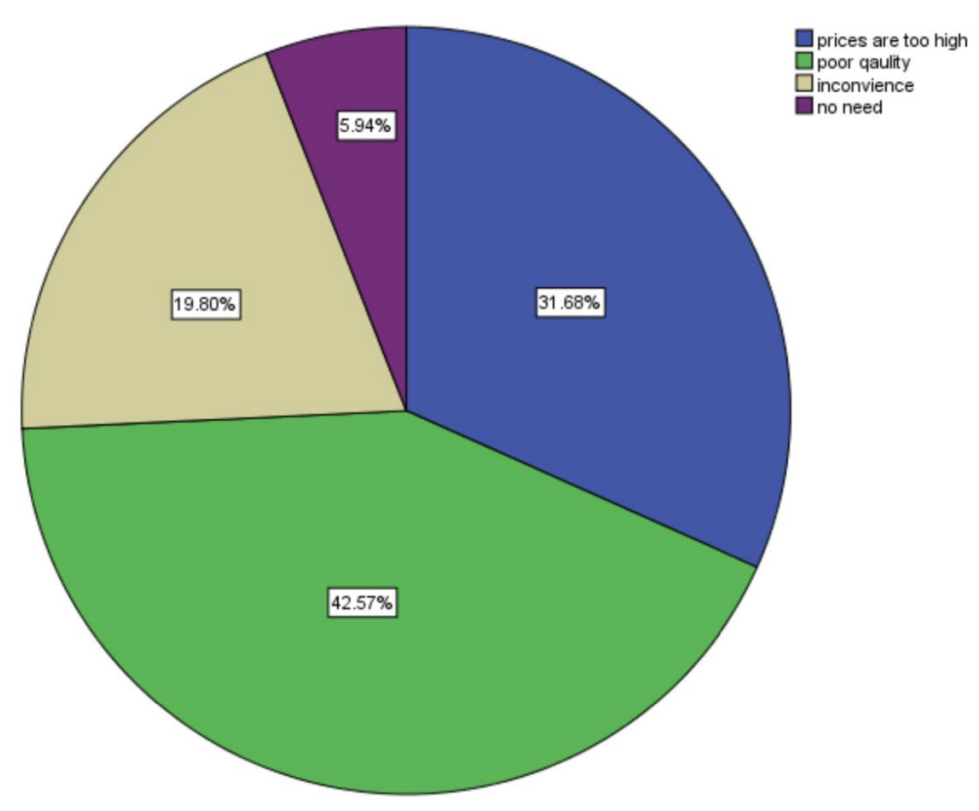

Figure 6: This graph represents the distribution of study population based on factors affecting the purchasing choice of electric toothbrush, $\mathbf{4 2 . 5 7 \%}$ of participants responded to the poor quality of brushes available, $31.68 \%$ of participants responded that prices are too high, $\mathbf{1 9 . 8 0 \%}$ of participants responded to inconvenience in maintaining those brushes and $5.94 \%$ of participants responded that there was no need. 


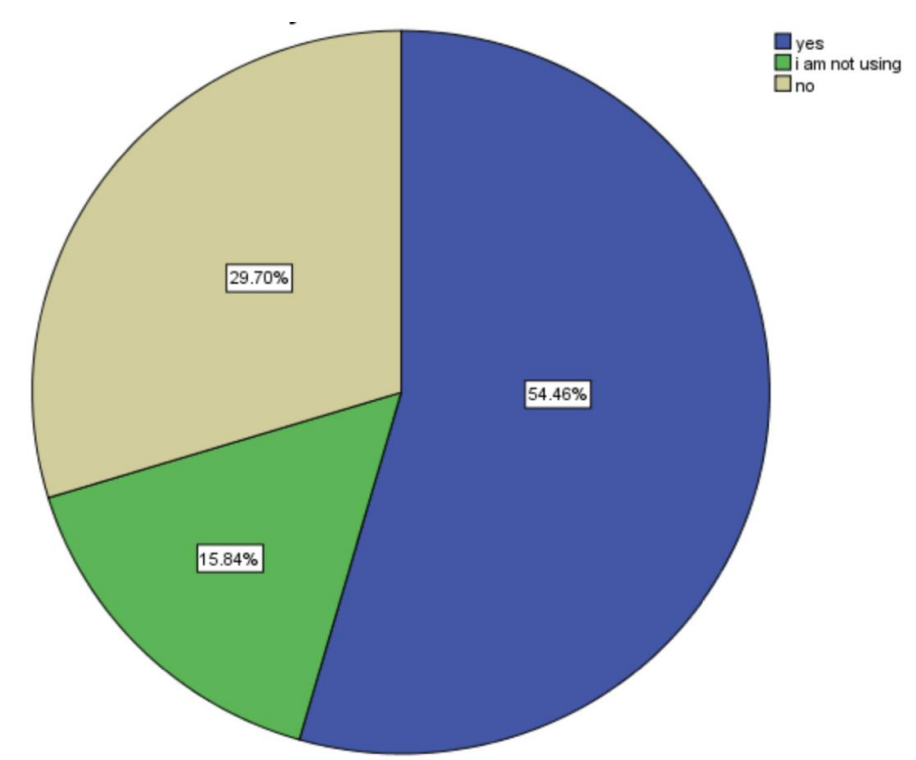

Figure 7: This graph represents the distribution of study population based on affinity for electric toothbrushes, $54.46 \%$ of participants responded that yes, $15.84 \%$ of participants responded that I am not using and $29.70 \%$ of participants responded that no.

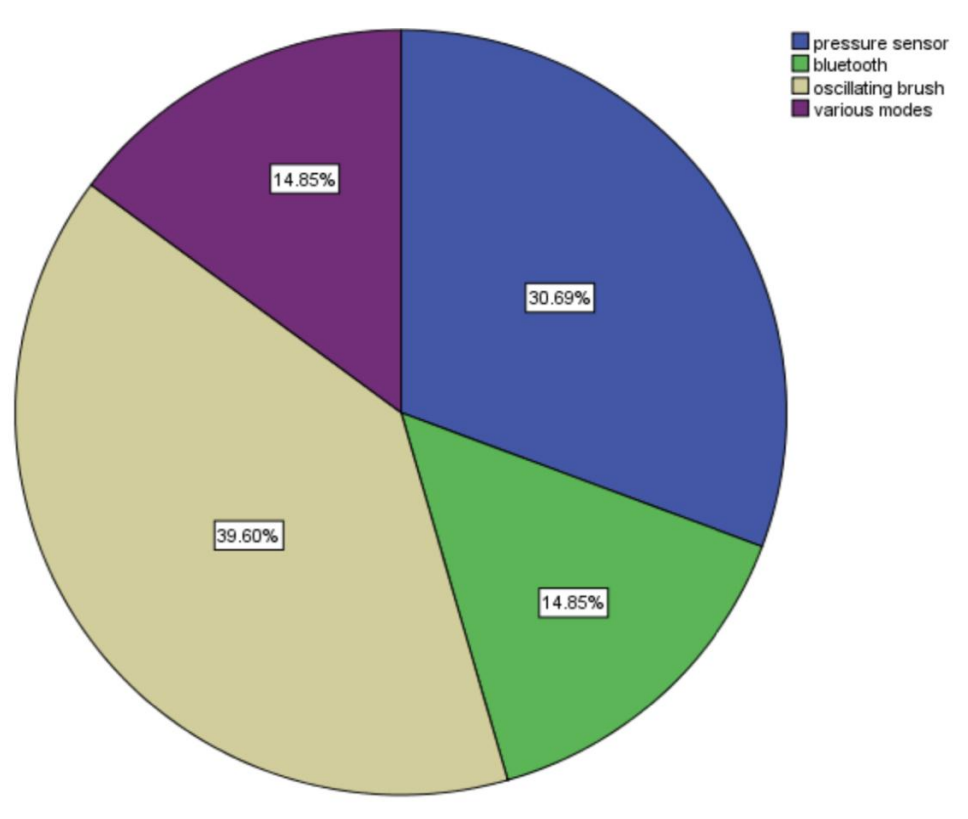

Figure 8: This graph represents the distribution of study population based on additional features of an electric toothbrush, 30.69\% of participants are aware of the pressure sensor, $39.60 \%$ of participants are aware of oscillating brush, $\mathbf{1 4 . 8 5 \%}$ of participants are aware of Bluetooth and $14.85 \%$ of participants are aware of various modes that can be used in electric toothbrushes. 


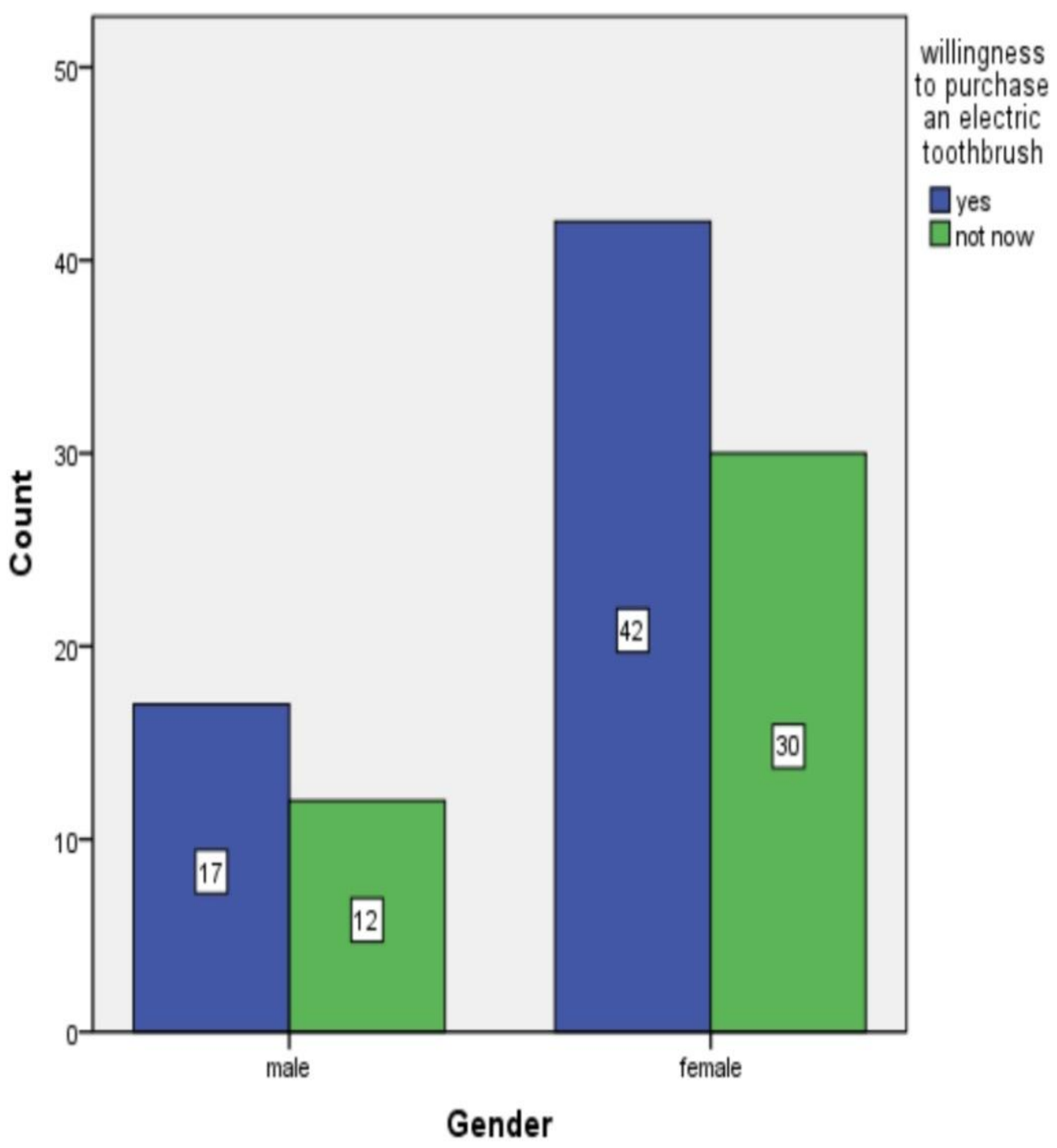

Figure 9: Bar chart represents the association between gender and their willingness to purchase an electric toothbrush. $X$ axis represents gender and $Y$ axis represents frequency of willingness to purchase an electric toothbrush. Chi square test was done and association was found to be statistically not significant. Pearson's chi square value: $0.001, \mathrm{DF}: 1$, p value : $0.979(<0.05)$ hence statistically not significant, proving there is similar level of willingness about purchase of an electric toothbrush in both the genders. 


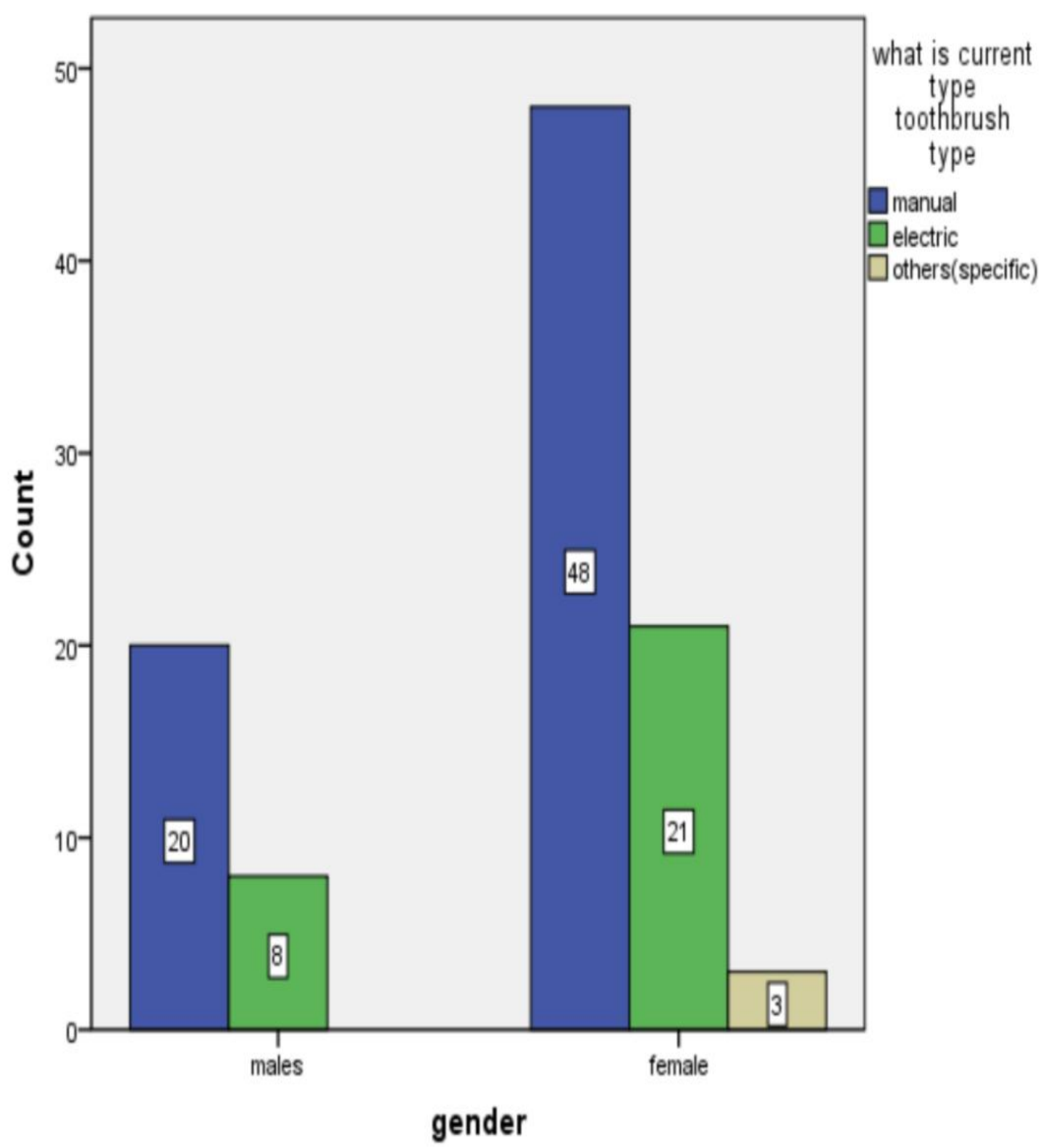

Figure 10: Bar chart represents association between gender and their current toothbrush type used. $X$ axis represents gender and $\mathrm{Y}$ axis represents frequency of responses regarding current toothbrush type. Chi square test was done and association was found to be statistically not significant. Pearson's chi square value : 1.326 , DF: 2 , p value: $0.515(<0.05)$ hence statistically not significant, proving female and male both are more commonly using manual toothbrushes and there is no gender variation. 


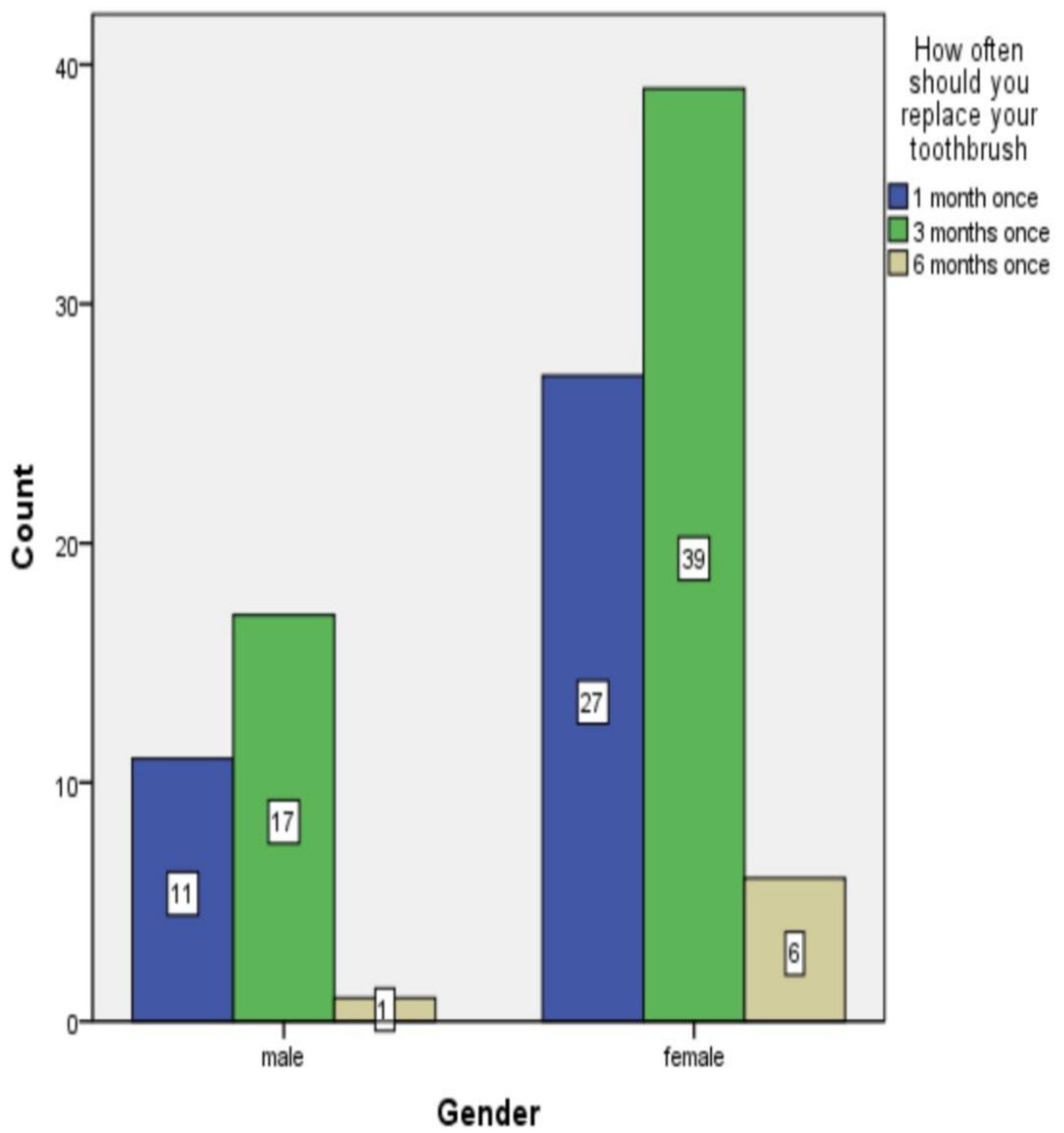

Figure 11: Bar chart represents association between gender and frequency of changing the tooth brush. $X$ axis represents gender and $Y$ axis represents responses regarding frequency of changing. chi square test was done and association was found to be statistically not significant. Pearson's chi square value; $0.787, \mathrm{DF}: 2, \mathrm{p}$ value: $0.675(<0.05)$ hence statistically not significant, proving both male and female are changing their brush 3 months once and there is no gender variation. 


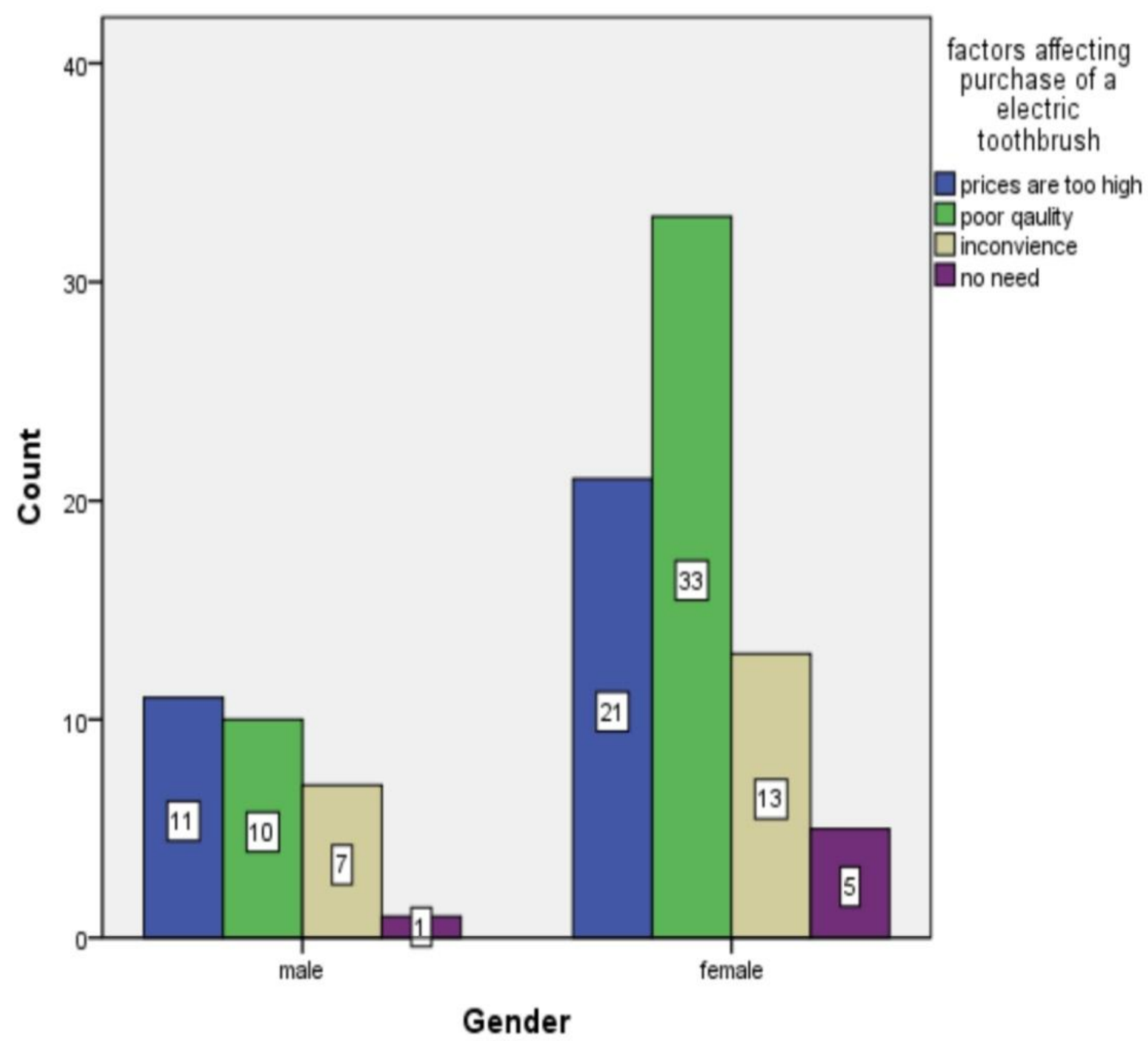

Figure 12: Bar chart represents association between gender and factors affecting purchasing choice of electric toothbrushes. $X$ axis represents gender and $Y$ axis represents the number of respondents relating the factors affecting purchasing choice of electric toothbrushes. Chi square test was done and association was found to be statistically not significant. Pearson's chi square value: 1.938 , DF: 3, p value: $0.585(<0.05)$ hence statistically not significant. This proves there is a similar level of awareness in both the gender about the factors that affect their choices of purchasing electric toothbrush. 


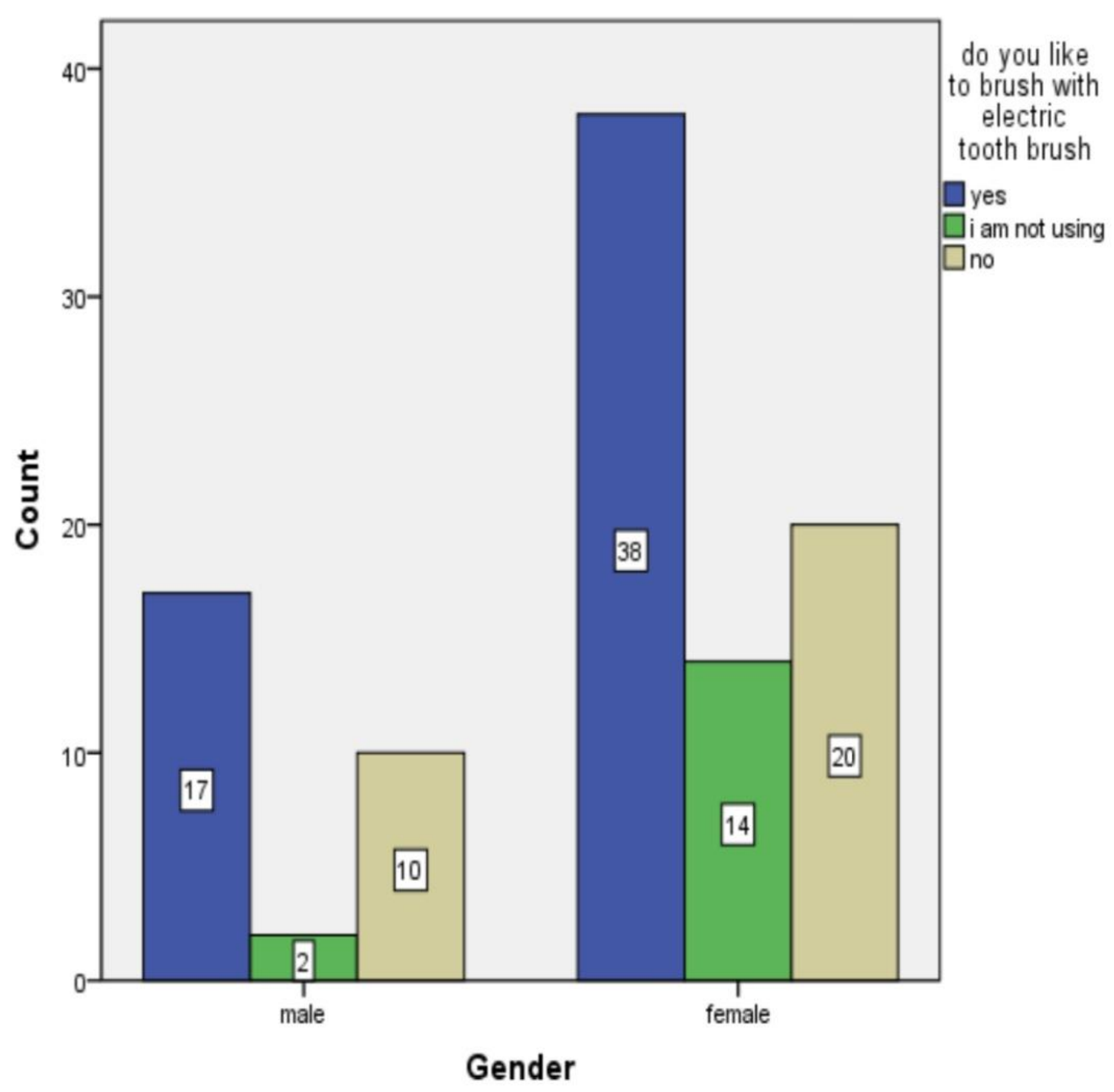

Figure 13: The bar chart represents the association between gender and affinity for electric toothbrushes. $X$ axis represents gender and $Y$ axis represents frequency of affinity for electric toothbrushes. Chi square test was done and association was found to be statistically not significant. Pearson's chi square value: 2.497 , DF:2, p value: $0.287(<0.05)$ hence statistically not significant. This shows there is no gender variation regarding affinity for electric toothbrushes. 
In the current study the Figure 1 reveals the current toothbrush type among participants, the graph represents $71 \%$ of participants using manual toothbrush, $27 \%$ of participants using electric toothbrush. Figure 2 depicts that replacement of tooth brushes among the participants, the graph represents $58 \%$ of participants replacing their toothbrush 3 months once, $35 \%$ of participants replacing their tooth brush once a month and $7 \%$ of participants replacing their toothbrush 6 months once. Figure 3 reveals that which toothbrush is feeling better for brushing, the graph represents $66 \%$ of participants responded that bluetooth brushing is feeling better and $34 \%$ of participants responded that manual brushing is feeling better. Figure 4 represents that comfortable with the current way of cleaning your teeth and satisfied with the cleaning results, the graph represents $33 \%$ is very satisfied, $38 \%$ it is sufficient, $21 \%$ is it could be improved. Figure 5 depicts that willingness to purchase an electric toothbrush, the graph represents $61 \%$ of participants are willing to purchase an electric toothbrush and $39 \%$ of participants say not now. Figure 6 depicts that the potential factors that affect your purchasing choice of electric toothbrush, the graph represents $41 \%$ of participants responded that prices are too high, $36 \%$ of participants responded to that poor quality, $18 \%$ of participants responded to that inconvenience. Figure 7 depicts that you like to brush your teeth with an electric toothbrush? The graph represents $58 \%$ of positive responses, $28 \%$ of negative responses and $15 \%$ of participants say I am not using it. Figure 8 reveals that useful additional features of an electric toothbrush, the graph represents $37 \%$ of Bluetooth, $35 \%$ of pressure sensor, $15 \%$ of oscillating brush. In our study there are specific limitations linked to the data gathering method. The bar graph through figure 9 to figure 13 depicts that association between gender on willingness to purchase Bluetooth toothbrush (Figure 9); association between gender on current toothbrush type used (Figure 10); association between gender on frequency of changing toothbrush (Figure 11); association between gender on choice purchasing toothbrush types (Figure 12) and association between gender on affinity for electric toothbrushes (Figure 13). From (Figure 9 to Figure 13) $\mathrm{P}$ value is greater than $0.05 ; \mathrm{p}$ value $>0.05$ ) and was not found to be statistically significant. Therefore the different factors related to purchase, willingness to use, frequency of changing toothbrush and affinity for electric toothbrushes have no statistically significant 
difference between the male and female of the population.

In our study there are specific limitations linked to the data gathering method. Online surveys are simple to set up and do not require a physical contact between the interviewers and the respondents that was a concern during COVID-19 outbreak. However, online surveys raise the limit of sampling methods they cannot reach people that are not comfortable with technology or don't have access to technology or the internet, such as low income, poorly educated persons or elderly. Moreover, online surveys do not allow a deep analysis of the results. This can be achieved through qualitative studies. Oral hygiene has been identified as the predominant and inevitable component of preventing oral diseases [6]. Including gingivitis and periodontitis, for which various mechanical and chemical oral hygiene aids have been formed. In our study $66 \%$ of participants used manual brushing and $34 \%$ of participants used electric toothbrushes (Figure 1). The bar chart represents the association between gender and current toothbrush type used (Figure 10). In a similar study $96 \%$ of the transgender population were not aware of electronic brushes. $58 \%$ of the participants like to brush our teeth with electric toothbrushes. It represents factors affecting purchasing choice of electric toothbrushes, responses are $41 \%$ of participants responded that prices are too high, $36 \%$ of participants responded that poor quality, $18 \%$ of participants responded to that inconvenience (Figure 6). The bar chart represents association between gender and factors affecting purchasing choice of electric toothbrushes (Figure 12). This study shows that a low number of participants only use electric toothbrushes and there is no willingness to buy electric toothbrushes because prices are too high. This study dealt with only a limited population and if done with a large population can yield further results. This study is helpful to increase the knowledge and awareness of Bluetooth brushing among people.

\section{CONCLUSION}

Within the limitation of this study following conclusions can be drawn,

Knowledge of using Bluetooth brushing was found to be inadequate among the respondents included in this study, there are no gender discrepancies regarding the knowledge or perceptions regarding bluetooth brushing among the study participants. This study had a positive impact showing a moderate level of knowledge among participants. 


\section{REFERENCE}

[1] Institute NC, National Cancer Institute. Oral Hygiene [Internet]. Definitions. 2020. Available from: http://dx.doi.org/10.32388/kp9sh3

[2] Petersen PE. Challenges to improvement of oral health in the 21 st century - the approach of the WHO Global Oral Health Programme [Internet]. Vol. 54, International Dental Journal. 2004. p. 329-43. Available from: http://dx.doi.org/10.1111/j.1875595x.2004.tb00009.x

[3] Petersen PE. Improvement of oral health in Africa in the 21st century the role of the WHO Global Oral Health Programme [Internet]. Vol. 1, African Journal of Oral Health. 2004. Available from: http://dx.doi.org/10.4314/ajoh.v1i1.31 299

[4] Clarkson J. The effectiveness of evidence-based oral hygiene advice and instruction upon patient oral hygiene and self reported behaviour: a randomised controlled trial [Internet]. http://isrctn.org/>. Available from: http://dx.doi.org/10.1186/isrctn15791 152
[5] Judd J. Setting standards in the evaluation of community-based health promotion programmes-- a unifying approach [Internet]. Vol. 16, Health Promotion International. 2001. p. 367-80. Available from: http://dx.doi.org/10.1093/heapro/16.4. 367

[6] Rogers J. Evidence-Based Oral Health Promotion Resource. 2011. $122 \mathrm{p}$.

[7] Basha FYS, Ganapathy D, Venugopalan S. Oral Hygiene Status among Pregnant Women [Internet]. Vol. 11, Research Journal of Pharmacy and Technology. 2018. p. 3099. Available from: http://dx.doi.org/10.5958/0974360x.2018.00569.3

[8] Davies RM, Davies GM, Ellwood RP. Prevention. Part 4: Toothbrushing: what advice should be given to patients? Br Dent J. 2003 Aug 9;195(3):135-41.

[9] Scutt JS, Swann CJ. The first mechanical toothbrush? [Internet]. Vol. 139, British Dental Journal. 1975. p. 152-152. Available from: http://dx.doi.org/10.1038/sj.bdj.48035 38

[10] McCracken GI, Janssen J, Swan M, 
Steen N, de Jager M, Heasman PA.

Effect of brushing force and time on plaque removal using a powered toothbrush [Internet]. Vol. 30, Journal of Clinical Periodontology. 2003. p. 409-13. Available from: http://dx.doi.org/10.1034/j.1600051x.2003.20008.x

[11] Heasman PA, McCracken GI. Powered toothbrushes: a review of clinical trials [Internet]. Vol. 26, Journal of Clinical Periodontology. 1999. p. 407-20. Available from: http://dx.doi.org/10.1034/j.1600051x.1999.260701.x

[12] McCracken GI, Chapple IL, Milward M, Steen N, deJager M, Heasman PA. Efficacy of a prototype brush head for a powered toothbrush. A multicentre study [Internet]. Vol. 29, Journal of Clinical Periodontology. 2002. p. 889-95. Available from: http://dx.doi.org/10.1034/j.1600051x.2002.291003.x

[13] Glass RL. A Clinical Study of Hand and Electric Toothbrushing [Internet]. Vol. 36, Journal of Periodontology. 1965. p. 322-7. Available from: http://dx.doi.org/10.1902/jop.1965.3
6.4 .322

[14] Abraham P. Oral-B: Oral-B 7000 Smartseries Rechargeable Power Electric Toothbrush with 3 Replacement Brush Heads, Bluetooth Connectivity and Travel Case, Black, Powered by Braun. Independently Published; 2018. 36 p.

[15] Niemi M-L, Ainamo J, Etemadzadeh H. Gingival abrasion and plaque removal with manual versus electric toothbrushing [Internet]. Vol. 13, Journal of Clinical Periodontology. 1986. p. 709-13. Available from: http://dx.doi.org/10.1111/j.1600051x.1986.tb00869.x

[16] Grender J, Adam R, Zou Y. The effects of oscillating-rotating electric toothbrushes on plaque and gingival health: A meta-analysis. Am J Dent. 2020 Feb;33(1):3-11.

[17] Walji MF, Coker O, Valenza JA, Henson H, Warren-Morris D, Zhong L. A persuasive toothbrush to enhance oral hygiene adherence. AMIA Annu Symp Proc. 2008 Nov $6 ; 1167$.

[18] Duraisamy R, Krishnan CS, Ramasubramanian $\mathrm{H}$, 
Sampathkumar J, Mariappan S,

Navarasampatti Sivaprakasam A.

Compatibility of Nonoriginal Abutments With Implants:

Evaluation of Microgap at the Implant-Abutment Interface, With Original and Nonoriginal Abutments. Implant Dent. 2019 Jun;28(3):289-95.

[19] Selvan SR, Ganapathy D. Efficacy of fifth generation cephalosporins against methicillin-resistant Staphylococcus aureus-A review [Internet]. Vol. 9, Research Journal of Pharmacy and Technology. 2016. p. 1815. Available from: http://dx.doi.org/10.5958/0974360x.2016.00369.3

[20] Ganapathy D, Sathyamoorthy A, Ranganathan $\mathrm{H}$, Murthykumar $\mathrm{K}$. Effect of Resin Bonded Luting Agents Influencing Marginal Discrepancy in All Ceramic Complete Veneer Crowns. J Clin Diagn Res. 2016 Dec;10(12):ZC6770.

[21] Jain A, Ranganathan H, Ganapathy D. Cervical and incisal marginal discrepancy in ceramic laminate veneering materials: A SEM analysis [Internet]. Vol. 8,
Contemporary Clinical Dentistry. 2017. p. 272. Available from: http://dx.doi.org/10.4103/ccd.ccd_1 56_17

[22] Vijayalakshmi B, Ganapathy D. Medical management of cellulitis [Internet]. Vol. 9, Research Journal of Pharmacy and Technology. 2016. p. 2067. Available from: http://dx.doi.org/10.5958/0974360x.2016.00422.4

[23] Ganapathy DM, Kannan A, Venugopalan S. Effect of Coated Surfaces influencing Screw Loosening in Implants: A Systematic Review and Metaanalysis [Internet]. Vol. 8, World Journal of Dentistry. 2017. p. 496502. Available from: http://dx.doi.org/10.5005/jpjournals-10015-1493

[24] Ashok V, Suvitha S. Awareness of all ceramic restoration in rural population [Internet]. Vol. 9, Research Journal of Pharmacy and Technology. 2016. p. 1691. Available from: http://dx.doi.org/10.5958/0974360x.2016.00340.1

[25] Ashok V, Nallaswamy D, Benazir Begum S, Nesappan T. Lip Bumper 
Prosthesis for an Acromegaly

Patient: A Clinical Report [Internet].

Vol. 14, The Journal of Indian

Prosthodontic Society. 2014. p.

279-82. Available from:

http://dx.doi.org/10.1007/s13191-

013-0339-6

[26] Ajay R, Suma K, Ali S, Sivakumar JK, Rakshagan V, Devaki V, et al. Effect of surface modifications on the retention of cement-retained implant crowns under fatigue loads: An In vitro study [Internet]. Vol. 9, Journal of Pharmacy And Bioallied Sciences. 2017. p. 154. Available from:

http://dx.doi.org/10.4103/jpbs.jpbs 14617

[27] Jain AR, Nallaswamy D, Ariga P. Determination of Correlation of Width of Maxillary Anterior Teeth with Extraoral Factor (Interpupillary Width) in Indian Population [Internet]. JOURNAL OF CLINICAL AND DIAGNOSTIC RESEARCH. 2019. Available from: http://dx.doi.org/10.7860/jcdr/2019/ 41082.12988

[28] Jyothi S, Robin PK, Ganapathy D, Anandiselvaraj. Periodontal Health Status of Three Different Groups
Wearing Temporary Partial Denture [Internet]. Vol. 10, Research Journal of Pharmacy and Technology. 2017. p. 4339. Available from: http://dx.doi.org/10.5958/0974360x.2017.00795.8

[29] Subasree S, Murthykumar K, Dhanraj. Effect of Aloe Vera in Oral Health-A Review [Internet]. Vol. 9, Research Journal of Pharmacy and Technology. 2016. p. 609. Available from:

http://dx.doi.org/10.5958/0974-

360x.2016.00116.5

[30] Kannan A, Venugopalan S. A systematic review on the effect of use of impregnated retraction cords on gingiva [Internet]. Vol. 11, Research Journal of Pharmacy and Technology. 2018. p. 2121. Available from: http://dx.doi.org/10.5958/0974360x.2018.00393.1

[31] Venugopalan S, Ariga P, Aggarwal P, Viswanath A. Magnetically retained silicone facial prosthesis. Niger J Clin Pract. 2014 Mar;17(2):260-4. 